Table 1 Selected Zika vaccines in development

\begin{tabular}{|c|c|}
\hline Developer (location) & Product \\
\hline \multicolumn{2}{|l|}{ In trials } \\
\hline $\begin{array}{l}\text { GeneOne Life Science/Inovio } \\
\text { (The Woodlands, Texas) }\end{array}$ & $\begin{array}{l}\text { GLS5700 DNA vaccine containing pre-membrane and envelope } \\
\text { protein }\end{array}$ \\
\hline NIAID & VRC-ZKADNA085-00-VP \\
\hline Sanofi & Purified inactivated virus vaccine \\
\hline \multicolumn{2}{|l|}{ In preclinical development } \\
\hline \multirow{2}{*}{$\begin{array}{l}\text { Immunovaccine (Halifax, Nova } \\
\text { Scotia, Canada) }\end{array}$} & DepoVax-Zika vaccine \\
\hline & Adjuvant plus antigen in liposome, suspended in oil \\
\hline GeneOne Life Science & $\begin{array}{l}\text { GLS5700 DNA vaccine containing pre-membrane and envelope } \\
\text { protein }\end{array}$ \\
\hline GeoVax Labs (Smyrna, Georgia) & $\begin{array}{l}\text { GOVX-ZM01 modified vaccinia virus Ankara-virus-like particle } \\
\text { vaccine }\end{array}$ \\
\hline Replikins (Boston) & Trivalent vaccine for Zika, dengue and Japanese encephalitis \\
\hline $\begin{array}{l}\text { VBI Vaccines (Cambridge, } \\
\text { Massachusetts) }\end{array}$ & Zika eVLP bivalent vaccine with E glycoprotein and NS1 glycoprotein \\
\hline $\begin{array}{l}\text { Moderna Therapeutics (Cambridge, } \\
\text { Massachusetts) }\end{array}$ & Zika mRNA vaccine \\
\hline $\begin{array}{l}\text { Emergent BioSolutions } \\
\text { (Gaithersberg, Maryland) }\end{array}$ & Zika vaccine using BARDA vaccine platform \\
\hline $\begin{array}{l}\text { Ennaid Therapeutics (Alpharetta, } \\
\text { Georgia) }\end{array}$ & Zika vaccine with peptide fusion inhibitors \\
\hline Hawaii Biotech (Honolulu, Hawaii) & Zika vaccine using recombinant proteins made in insect cell lines \\
\hline $\begin{array}{l}\text { Protein Sciences (Meriden, } \\
\text { Connecticut) }\end{array}$ & Zika vaccine based on recombinant variants of $E$ protein \\
\hline $\begin{array}{l}\text { VLP Therapeutics (Gaithersberg, } \\
\text { Maryland) }\end{array}$ & Zika vaccine using i-alpha VLP technology \\
\hline Valneva (Lyon, France) & VLA1601 inactivated Zika vaccine \\
\hline Vaxart (S. San Francisco, California) & Non-replicating adenovirus type-5-vector-based Zika vaccine \\
\hline $\begin{array}{l}\text { Atheric Pharmaceutical (Troy, } \\
\text { Virginia) }\end{array}$ & Repurposed marketed drugs \\
\hline Bharat Biotech (Genome Valley, & ZikaVAC inactivated virus \\
\hline Hyderabad, India) & ZikaVAC recombinant vaccine using viral surface antigens \\
\hline
\end{tabular}

BARDA, The Biomedical Advanced Research and Development Authority; eVLP, enveloped virus like particle. Source: BioMedTracker, clinicaltrials.gov, company websites

Tang at Florida State University in Tallahassee, who had a small NIH-funded program on dengue. In January, when his group was preparing to make a large batch of dengue virus, he switched gears immediately to Zika. Between then and now, his group, in collaboration with neuroscientists Hongjun Song and Guo-Li Ming at Johns Hopkins University in Baltimore, and Wei Zheng, at NIH's National Center for Advancing Translational Sciences (NCATS), published a series of papers relating to the virus's effects on neuronal cells (neural progenitor cells, astrocytes and brain organoids developed from induced pluripotent stem cells) (Cell 165, 1238-1254, 2016). The team also identified small molecules that inhibit Zika virus replication from an NCATS repurposing library of 6,000 compounds (Nat. Med. 22, 1101-1107, 2016). Their hits fall into two categories, inhibitors of Zika infection in human central nervous system cells and inhibitors of Zika-induced caspase activity, which causes neuronal cell death.

Tang and collaborators are moving forward, testing compounds that either protect neurons from Zika-virus-induced caspase or have antiviral activity. The team are "going deep and going broad," says Tang, gearing up to conduct preclinical studies with the repurposed drug Niclocide (niclosamide), approved by the US Food and Drug Administration for treating worm infections in humans and livestock, after they found it inhibited Zika replication in their screen. The researchers have also developed a specific assay for Zika replication, which they have used for rescreening the compound library (unpublished data). Tang has pieced together internal funding from his university with some external grants to support this work and, in August, a pharma holding company based in West Des Moines, Iowa, Spotlight Innovations, stepped in with several years of funding. The agreement gives the company the right to license any intellectual property that comes from the sponsorship.

Similarly, Barouch's team began work in early 2016 following reports about the epidemic in Brazil and the World Health Organization's declaring a global health emergency. With the help of three Brazilian post-docs working in his laboratory and their contacts, they were able to

\section{Mutanome draws Genentech deal}

Immunotherapy developer BioNTech of Mainz, Germany, has partnered with Roche's Genentech unit to develop, manufacture and commercialize novel mRNA-based, individualized cancer vaccines. The strategic collaboration combines S. San Franciscobased Genentech's cancer immunotherapy portfolio and research program with BioNTech's proprietary Individualized Vaccines Against Cancer (IVAC) clinical platform that uses next-generation sequencing of a patient's cancer genome to identify an array of unique mutations, known as the tumor 'mutanome', that potentially encodes for neoantigens. These neoantigens can be exploited by making an mRNA vaccine encoding selected neoantigens for each individual tumor's mutanome signature, triggering an immune response highly specific to the tumor. The approach could result in precisely targeted cell death in a broad range of cancers. "Unlike any medicine we have ever developed, virtually all cancer patients may potentially benefit from a custom built cancer vaccine," said James Sabry, senior vice president and global head of Genentech partnering. "By collaborating with BioNTech on this cutting edge approach, we hope to truly advance cancer treatments by using a common molecular backbone-mRNA - that is uniquely tailored to an individual patient." Genentech agreed to pay BioNTech $\$ 310$ million in upfront and near-term milestone payments, and the two companies will share all development costs and any potential profits, with BioNTech retaining the right to co-promote certain products that arise from the agreement in the US, Germany and several other markets. The deal with Genentech follows previously announced collaborations with Bayer for new mRNA vaccines and therapeutics for animal health applications, and Sanofi for cancer immunotherapies. 